\title{
¿Y después de Sagunto, qué? Las bases del orden restauracionista en Lugo (1875-1881)
}

\author{
Xosé R. Veiga Alonso *
}

RESUMEN

El objetivo de esta investigación es realizar un estudio de las bases politicas y sociales que definen los primeros años de la Restauración en el Lugo decimonónico. En general, los origenes de la Restauración se han analizado desde una perspectiva centralista que privilegiaba el papel de los políticos actuantes en el centro madrileño. En este articulo, por el contrario, se adopta una visión periférica que concede el protagonismo a los actores locales $y$

provinciales. El estudio del activo papel de los alfonsistas lucences, de la peculiar traducción provincial de las disposiciones renovadores de diputaciones, ayuntamientos y empleados públicos, del papel del gobernador civil siempre muy condicionado por los políticos de la provincia o de los sólidos espacios de poder que se estructuran alrededor de

\section{ABSTRACT}

The aim of this investigation is to carry out a study of the social and political basis which define the first years of the Restoration in Lugo in the 19th century. Generally, the origins of the Restoration have been analized from a centralist idea which favoured the role of the politicians settled in the centre of Madrid. On the contrary, in this article, local and provincial actors are treated as the protagonist from a peripheral point of view. The study of the active part of the "alfonsistas" of Lugo, the study of the special provincial translation of the renewed ideas of the deputations, councils and public employers, the study of the civil gobernor always condicionated by the provincial politicians and the study of the power arranged around these powerful people, define a very changeable complex stage which can't only be explained from the

* Dpto. de Historia Contemporánea e de América. Universidade de Santiago de Compostela. 
estos poderosos provinciales, define un escenario de cambio muy complejo

que en absoluto puede explicarse recurriendo únicamente al análisis de las ordenanzas gubernamentales y al conocimiento del activismo de los políticos capitalinos.

\section{PALABRAS CLAVE Historia política, Restauración borbónica, siglo XIX, Lugo, política \\ provincial.}

governmental point of view or from the activist knowledge of the politicians of the capital.

\section{KEY WORDS}

Political history, Restoration, 19th century, Lugo, provincial political.

El 29 de diciembre de 1874, en una localidad cercana a Sagunto, el general Martínez Campos da por concluida la experiencia del Sexenio con su proclamación de Alfonso XII como nuevo rey de España. De inmediato, el jefe de filas de los alfonsistas, Antonio Cánovas del Castillo, se sitúa al frente de un Ministerio-Regencia encargado de dirigir los destinos del país, poniendo en marcha el político malagueño una estrategia de actuación guiada por un claro objetivo: resituar sobre nuevas bases la organización político-constitucional del país. De modo general, y salvo contadas excepciones ${ }^{1}$, este proceso ha sido analizado desde una posición centralista, de tal modo que el correlato inmediato y automático de cualquier decisión adoptada en Madrid era su correspondiente cumplimiento en provincias, dando así la impresión de que toda la complejidad del acontecer histórico quedaba reducida al estudio de los decretos y ordenanzas publicados en la Gaceta obviando el análisis de su plasmación concreta en la comunidad sociopolítica a la que iban dirigidos. De algún modo, estos estudios transmitian la sensación de una historia contruida en el vacío que ignoraba a una parte sustancial de sus protagonistas (todos aquellos alejados del sanctasanctórum madrileño), que debian conformarse con el poco envidiable papel de simples comparsas ejecutoras de órdenes y dictados originados en lejanos, oscuros y casi incomprensibles universos.

Muy en especial, los artículos de B. DE RIQUEA I PERManyen ("Burgesos, polítics i cacics a la Catalunya de la Restauració», L'avenç, núm. 85 (1985), pp. 16-33; «El conservadorisme politic català: del fracàs del moderantisme al desencís de la Restauración, Recerques, núm. 11 (1981), pp. 29-80) y J. CASASSAS, Entre Escilla i Caribdis. El catalanisme i la Catalunya conservadora de la segona mejtat del segle XIX, Barcelona, Edicións de la Magrana, 1990, especialmente pp. 126-34. 
Así, conocemos con mayor o menor exactitud el papel que en la solución restauradora juegan el colectivo de alfonsistas reunidos alrededor de Cánovas, pero mucho menos el de sus homónimos provincianos que laboraron por idéntico objetivo. De igual forma, sabemos de las ordenanzas renovadoras en 1875 de instituciones públicas como ayuntamientos y diputaciones, pero mucho menos del cómo se llevaron adelante tales cambios, de la hondura de los relevos realizados, de los criterios reales que en el espacio provincial los guiaron, de las implicaciones que tuvieron (y las lecturas a que dieron lugar lugar) en el ámbito local y, sobre todo, de las dificultades encontradas en su realización. Otro tanto se puede afirmar del papel reservado en estos años de transición a una figura tan mencionada como necesitada de estudios específicos cual es la del gobernador civil $^{2}$, por lo general presentado como un puntual ejecutor de la política de centralización gubernamental y dotado en cuanto tal de todos los intrumentos de coacción a disposición del ejecutivo, cuando en la realidad su actuación puede moverse en un ámbito de mayor autonomía respecto de las disposiciones madrileñas y aparecer menos como todopoderoso aliado del gobierno y más como una figura fuertemente condicionada en su actuación por las presiones de los poderosos locales. También sobre los empleados del Estado se ha hecho recaer el papel de fieles agentes gubernamentales analizándose las frecuentes variaciones de que eran objeto con cada cambio de goberno como una reacomodación de la estructura funcionarial al nuevo partido en el poder, pero por lo general no se ha reflexionado sobre quienes eran los verdaderos responsables de las cesantías y los nuevos nombramientos, provocándose de nuevo la sensación de una adaptación simple y automática de la periferia a las variaciones habidas en el centro y obviándose el fundamental papel jugado en este proceso por las fuerzas locales. Por último, hay igualmente que hacer referencia a la dinámica electoral y a la recomposición habida en la representación parlamentaria, que en absoluto puede entenderse como fruto exclusivo del encasillado gubernamental por cuanto la fortaleza y los apoyos en el distrito de los candidatos deben de ser igualmente integrados (y justamente valorados) en la explicación final de su elección. El objetivo de las siguientes páginas no será otro que el de intentar arrojar alguna luz sobre éstas y otras cuestiones en referencia a la provincia de Lugo.

Si bien algunos estudios están comenzando a paliar esta situación: M. RISQuEs, El Govern Civil de Barcelona al segle XIX, Barcelona, Publicacions de l'Abadia de Monserrat, 1995; A. CAJAL VALERO, El Gobernador Civil y el Estado centralizado del siglo xix, Madrid, MAP, 1999. También, F. SuARez, Memorias del gobernador Antonio Guerola II. Sevilla, 1876-78, Sevilla, Fundación Sevillana de Electricidad, 1993. 


\section{LA CONCRECIÓN DEL ALFONSISMO LUCENSE}

Al igual que ocurre en el resto del país, los moderados lucenses quedan por completo descolocados ante el golpe democrático de 1868 cayendo en una situación de completa desorganización. Acostumbrados como estaban a ejercer un dominio absoluto sobre las instituciones, el hecho de quedar ahora fuera de ellas suponía un golpe especialmente duro para sus intereses, máxime cuando su siempre cercana posición al poder habia inhibido el desarrollo de órganos partidistas ${ }^{3}$, contribuyendo ahora esta carencia a acentuar la impresión de desorden y falta de unidad que los caracteriza durante los primeros años del Sexenio ${ }^{4}$. Así, y hasta 1871, apenas si tenemos noticias de actividad pública alguna por parte de la otrora poderosa facción moderada lucense. Sin embargo, y coincidiendo con la publicación de un manifiesto en noviembre de 1870 por parte de prominentes figuras del moderantismo, la situación comienza a mudar rápidamente de aspecto, de tal modo que ya en enero de 1871 funciona en Lugo una autodenominada "Comisión Provincial del Partido Conservador" que como objetivos inmediatos se plantea la reorganización de las huestes moderadas y la preparación de las futuras citas electorales ${ }^{5}$.

El análisis de los integrantes de la comisión no deja lugar a dudas en cuanto a su ubicación política. Se trata de antiguos moderados con experiencia política a sus espaldas. El cargo de presidente recae en el conde de Pallares, abogado de Vilalba, propietario importante (ocupa el puesto 48 entre los 50 mayores contribuyentes de la provincia: BOP de Lugo, n. $\left.{ }^{\circ} 125,19-X-1875\right)$ y dos veces representante en Cortes (1857 y 1863). Entre los vocales destacan Antonio Camba y Monasterio, abogado de Lugo, diputado provincial de modo casi ininterrumpido desde 1859 (currículo que incluye el cargo de presidente de la Diputación en 1864 y 1865) y viejo colaborador del Conde en sus proyectos políticos; Casiano Pérez Batallón, abogado de Sarria, diputado a Cortes en 1866 y rico propietario

Según A. Panebianco (Modelos de partido, Madrid, Alianza, 1995, p. 216), la disposición de amplios recursos públicos genera partidos caracterizados por un bajo desarrollo organizativo. En el mismo sentido, M. Duverger, Los partidos políticos, México, F.C.E., 1957, pp. 93-95.

4 Cartas del conde de Pallares a Calixto Varela (?-VI-1870, 1-VIII-1870) y a "Pepe" (?-XII1870). Las tres, en Arquivo Histórico Provincial de Lugo, sección Xeral, documentación do conde de Pallares, legajo 10 (en lo sucesivo, AHPL, CP).

5 Al manifiesto moderado alude F. GOMEZ OCHOA, «El conservadurismo canovista y los origenes de la Restauración: la formación de un conservadurismo moderno", en M. Suárez Cortina (ed.), La Restauración, entre el liberalismo y la democracia, Madrid, Alianza, 1997, p. 137. La formación de la Comisión lucense, en la carta de Pallares a Ramón Pardo Montero (22-1-1871). Semanas antes se habia fundado la coruñesa: carta de "Pepe" a Pallares (17-XII-1870). Las dos correspondencias, en AHPL, CP, leg. 11 y 10 , respectivamente. 
(puesto 41 entre los 50 mayores contribuyentes: BOP de Lugo, n. ${ }^{\circ} 20$, 15-II-1872); Alejandro Castro Gómez, abogado de Lugo, propietario, comerciante y ex-depositario de fondos provinciales, y Manuel Freire Calviño (que desempeña las labores de secretario), propietario de Cospeito y funcionario. El primer éxito que consiguen los reorganizados moderados es la elección del conde de Pallares como diputado provincial por el distrito de Trasparga (febrero de 1871) ${ }^{6}$, elección que no será sino el prólogo de un logro mucho mayor: la consecución por Pallares de la representación en Cortes del distrito de Vilalba, que sumadas a las obtenidas por los también moderados conde de Maceda y Mànuel Rodríguez de Castro (por Lugo y Monforte, respectivamente) suponían para el moderantismo lucense recuperar posiciones en el poder legislativo luego de más de dos años de forzado alejamiento?

A pesar de la etiqueta moderada con que acude el conde de Pallares a esta elección, lo cierto es que ya desde 1870 , como demuestra su correspondencia privada, se había mostrado partidario de la abdicación de Isabel II y de aunar esfuerzos en torno a la bandera del príncipe Alfonso, por cuanto consideraba que el partido moderado se encontraba por completo incapacitado para llevar adelante la restauración ${ }^{8}$. Por lo tanto, era claro que en la disputa interna de los apoyos borbónicos, divididos entre los que apostaban por la vuelta sin más al pasado y los partidarios de una restauración abierta a todos los monárquicos que aceptasen la opción alfonsina, el grupo lucense liderado por Pallares se situaria al lado de estos últimos, como efectivamente sucedió. De hecho, en las correspondencias de los últimos meses de 1871 ya no se alude tanto a la agrupación moderada como a la agrupación alfonsina, un cambio formal que en este contexto concreto tiene una lectura clara que avala la afirmación anterior. Con el nuevo año y la preparación para las elecciones de marzo de 1872 , el pa-

\footnotetext{
6. De hecho, estas elecciones provinciales suponen la aparición en la Diputación de un movimiento de oposición, integrado por carlistas y moderados-alfonsinos, a la obra del Sexenio en Lugo: Actas de la Diputación Provincial de Lugo (ADL), 17-11-1871 y ss.; El Eco de Galicia, núm. $47,16-\mathrm{XI}-1872$.

Recordemos que a las elecciones de marzo de 1871 acuden los moderados en coalición con carlistas y republicanos, hecho fundamental para entender sus buenos resultados. En la provincia de Lugo, cinco de los once escaños en lucha fueron parar a las oposiciones: Lugo (conde de Maceda, moderado), Monforte (Manuel Rodriguez de Castro, moderado), Chantada (Agustín María Saco y Quiroga, marqués de Villaverde, carlista), Sarria (Ramón Somoza Saavedra, carlista) y Vilalba (conde de Pallares, moderado). Para la adscripción política de estos diputados, carta de Pallares a Constantino de Ardanaz (13-VII-1872): AHPL, CP, leg. 11, y X. R. Barreiro FERNANDEZ, Historia Contemporánea. Politica (siglo XIX), en Galicia. Historia, t. VII, A Coruña, Hércules de Ediciones, 1991, p. 427.

* Carta de Pallares a Calixto Varela (?-VI-1870): AHPL, CP, leg. 10.
} 
norama acaba ya de clarificarse. Asi, las misivas que llegan a manos del conde de Pallares ya no se refieren a colaboradores y simpatizantes moderados sino a alfonsinos; del mismo modo, en las negociaciones electorales emprendidas con radicales, carlistas y republicanos la única agrupación presente es la alfonsina, en tanto que las referencias madrileñas dejan de ser moderados como Esteban Collantes o el conde de Heredia, substituidos ahora por lideres del alfonsismo (varios de ellos procedentes del unionismo) como Constantino de Ardanaz, el conde de Toreno, Barzanallana o Calderón Collantes.

Este año de 1872 resulta clave en el proceso de asentamiento del alfonsismo lucense. Por un lado, obtiene el pleno reconocimiento de la cúpula dirigente madrileña, como demuestra el hecho de que se haga recaer sobre los hombros del conde de Pallares la no fácil tarea de conseguir un acta de diputado para Constantino de Ardanaz, el ex-ministro revolucionario (había ocupado la cartera de Hacienda en el último gabinete presidido por Prim) que ya en varias ocasiones representara en Cortes al distrito lucense de Ribadeo entre 1857 y 1871, y que desde este año habia apostado fuertemente por la opción restauradora personificada en el príncipe Alfonso. Alejado ahora de toda veleidad revolucionaria, su concurso como político de peso era considerado importante para el alfonsismo, por lo que lograr convertirlo en diputado se presentaba como una urgente necesidad. Finalmente, consigue un acta por el distrito lucense de Chantada, y ésto gracias a las gestiones del conde de Pallares con Miguel Rodríguez Guerra, el más importante propietario de la zona (y uno de los más poderosos de toda la provincia: ocupa el puesto 22 entre los mayores pagadores en 1875), diputado a Cortes en cinco ocasiones entre 1851 y 1865 y que disponia de una gran fuerza electoral en el distrito, poderio que en esta ocasión sitúa en favor del candidato alfonsino C. de Ardanaz ${ }^{9}$. Su elección demostraba tanto la decidida apuesta integradora de los alfonsinos lucenses (al apoyar, como venian de hacer, a un hombre de la revolución) como la cada vez más sólida implantación que tenian en la provincia.

Más importante todavía que esta victoria electoral es la puesta en marcha, en agosto de 1872, del periódico El Eco de Galicia, que desde su primer número se presenta como el órgano de opinión de los alfonsistas de la provincia ${ }^{10}$. Fundado y dirigido por el conde de Pallares, cuenta entre

9 Cartas de Pallares a Rodríguez Guerra (16, 17 y 18-III-1872), Rodriguez Guerra a Pallares (20-III-1872) y Pallares a C. de Ardanaz (30-III-1872). Todas, en AHPL, CP, leg. 11

10 Dentro de la estrategia de actuación de los alfonsinos, el sostenimiento de cabeceras de prensa adictas fue uno de los aspectos más cuidados: M. Fernandez Almagro, Cánovas. Su vida 
sus sostenedores y redactores con los más selectos representantes del alfonsismo lucense, cuyo origen delata una común procedencia moderada que podemos presentar ya como característica básica de los apoyos borbónicos en Lugo. Algunos como Pallares, Antonio Camba, Alejandro Castro Gómez o Manuel Freire Calviño ya nos resultan conocidos como miembros de la Comisión Provincial conservadora, a los que ahora se añaden nombres como los de los abogados Nicandro García Taboada (ex-consejero provincial) y José María Castro Bolaño (diputado provincial en 1862 y 1863), como el del médico Segundo Castro Pita, como el del funcionario Teolindo María Romero o como el del secretario de la diputación provincial (y futuro gobernador de la provincia), Antonio de Medina. A partir de su aparición, el rotativo actuará cumpliendo la triple misión que es característica de toda publicación política, sirviendo de nexo de unión entre los correligionarios, de propagandista de su ideología y de defensor frente a los ataques de los adversarios, contribuyendo con las campañas desarrolladas desde sus páginas (por ejemplo, contra la ley de redención foral republicana que perjudicaba gravemente los intereses de los rentistas gallegos, 0 contra los intentos de reforma respecto de Cuba) a incrementar los apoyos del alfonsismo y a mantener encendida la llama de la restauración durante los difíciles meses de la / República. Por último, y para completar este año clave de 1872 , hay que hacer referencia al papel jugado por el conde de Pallares en la ardua labor de aunar voluntades alrededor del proyecto alfonsino, que lo llevará en junio de este año a realizar una gira por las provincias de Pontevedra y Ourense con el objeto de recabar firmas de adhesión al manifiesto alfonsista que tendrá en Cánovas a uno de sus más importantes apoyos".

Es concretamente en el distrito de Vilalba donde los alfonsinos concentran la mayoría de sus esfuerzos. La razón de esta centralidad es muy simple: la casa solariega del conde de Pallares se encuentra aquí, por lo que no es de extrañar que cuente en la zona con muchos e importantes apoyos,que desde 1871 comienza a movilizar en pro de la causa restauradora. En primer lugar, el propio Conde se nos aparece

\footnotetext{
y su politica, Madrid, Ambos Mundos, 1951, p. 242; J. Varela ORTega, Los amigos políticos. Partidos, elecciones y caciquismo en la Restauración (1875-1900), Madrid, Alianza, 1977, p. 32.

Cartas de Juan José Viñas (3-VII-1872), Ramón Pedrayo Silva (12-VII-1872) y Andrés Andrade (14-VII-1972) a Pallares: AHPL, CP, leg. 11. Ver igualmente, "Nota de las personas que más se han distinguido en la provincia de Lugo por sus servicios en favor de la restauración del trono legítimo y su amor a S. M. el Rey y su augusta dinastía, y títulos, honores y empleos que en concepto del que suscribe pudieran otorgárseles" (nota manuscrita del gobernador civil de Lugo, Antonio de Medina,): AHPL, CP. leg. 12 (correspondencia de 1875). De la adhesión de Cánovas al manifiesto informa J. VARELA ORTEGA, Los amigos políticos..., p. 28.
} 
como uno de los más importantes propietarios del distrito (459 pts. de contribución territorial en 1874) ${ }^{12}$, lo que en un contexto de electorado ampliado como es el del Sexenio resulta fundamental por las amplias posibilidades que el control del voto de caseros, arrendatarios y caseros ofrece de cara a las consultas electorales ${ }^{13}$. Pero tan importante como el patrimonio económico personal en forma de tierras y rentas, es la disposición de una amplia red de contactos sociales (desde familiares y amigos hasta correligionarios de partido) que estén en disposición de dirigir en determinada dirección los sufragios de sus dependientes agrarios y de actuar ellos mismos como decididos auxiliares políticos, y el conde de Pallares no andaba escaso de tales elementos dentro del distrito vilalbés: Pedro García Montenegro ( $3 .^{\circ}$ mayor pagador), Eleuterio Morandeira $\left(7 .{ }^{\circ}\right)$ y Pastor Maseda Vázquez de Parga $\left(8 .^{\circ}\right.$ y sobrino del Conde) en el ayuntamiento de Begonte; Manuel Freire Calviño $\left(5^{\circ}\right.$, funcionario) en el de Cospeito; José Pardo Domínguez $\left(1 .^{\circ}\right.$, familiar de Pallares, abogado), Fernando Sanjillao $\left(3 .^{\circ}\right)$ y Juan Manuel Pardo del Monte $\left(5 .^{\circ}\right.$, diputado provincial en 1867, abogado) en el de Outeiro de Rei; Ramón Pardo Montero (7. ${ }^{\circ}$, abogado, diputado provincial entre 1864-67, ex-alcalde, ex-juez de paz) y José Martínez Varela $\left(25 .^{\circ}\right.$, abogado) en el de Trasparga; Andrés Silva (1. ${ }^{\circ}$, diputado provincial entre 1858-66, abogado y escribano) y Andrés Basanta Olano (2. ${ }^{\circ}$ en el de Vilalba..., son algunos de los nombres que la correspondencia de estos años permite situar entre los más estrechos colaboradores de Pallares ${ }^{14}$. Por lo tanto, genuinos representantes de los notables locales, situados dentro del selecto grupo de los mayores contribuyentes de sus respectivos municipios y capacitados, tanto por su posición económica como por el prestigio e influencia sociales que aporta la propiedad y/o las funciones que desempeñan (aquí hay que resaltar muy especialmente la amplia representación de abogados), para actuar como eficaces agentes electorales en favor de la causa alfonsina.

Son éstos y otros apoyos (especialmente los de carlistas y republicanos que acuden coligados con los moderados en las elecciones de 1871), los que explican las dos victorias que, en las elecciones a Cortes de marzo de

"Repartimiento de la Contribución Territorial del Ayuntamiento de Villalba", leg. 109 (187475): AHPL, sección Facenda, serie Territorial.

13 La correspondencia de estos años está repleta de misivas reclamando (u ofreciendo) el voto cautivo de que son titulares los dependientes agrarios. Ver, por ejemplo, AHPL, CP, leg. 10.

${ }_{14}$ Excepto el dato referido a Andrés Silva, obtenido de la "Relación de los 50 contribuyentes que aparecen con mayor cuota por la de territorial..." (Boletin Oficial de la Provincia de Lugo, núm. 15, 31-(-1871), las restantes cuotas están sacadas de las listas electorales publicadas en el BOP de Lugo, núm. 111, 15-|X-1877. 
1871 y de agosto de 1872 (ahora ya con la etiqueta alfonsina), obtiene el Conde en el distrito de Vilalba. Del mismo modo, ayudan a entender el éxito que consiguen en las elecciones municipales celebradas a finales de 1871, y que se saldan con la presencia de partidarios de Pallares en varios de los ayuntamientos del distrito: en Vilalba vencen en cinco de los seis colegios (aunque finalmente no logran asegurarse el control de la corporación por la inhabilitación de varios de sus candidatos a concejales) ${ }^{15}$, en Begonte se hacen con la alcaldía y con la fiscalia municipal, en Outeiro de Rei con la alcaldía y las secretarías del ayuntamiento y el juzgado, en Trasparga con la alcaldía... ${ }^{16}$. Por lo tanto, la presencia alfonsina en todo el distrito se hacía cada vez más evidente, sin que la derrota cosechada en las elecciones a Cortes de abril de 1872 (célebres por la muy parcial actuación de Sagasta al frente del ministerio de la Gobernación) mermase en absoluto su moral ${ }^{17}$. Muy al contrario, las persecuciones, coacciones y amenazas sufridas (en las que se incluye un muerto en enfrentamientos con una partida de la porra gubernamental) no harán más que aumentar la cohesión entre los alfonsinos y su firmeza por continuar en la lucha.

En consecuencia, y para el caso concreto que ahora nos ocupa, parece claro que más allá del selecto círculo de políticos alfonsistas que actúan en Madrid, que más allá de la actividad restauradora de Cánovas, que más allá del activismo antirevolucionario de que da muestra la nobleza en sus círculos madrileños ${ }^{18}, y$ al igual que sucede en Cataluña, hay que señalar la presencia de activos grupos de partidarios del príncipe Alfonso que desarrollan su actividad en provincias, de individuos que, como en el ejemplo de los lucenses agrupados en torno del conde de Pallares, contribuyen de modo decisivo a la creación y difusión de ese estado social favorable al advenimiento de la Restauración que in-

\footnotetext{
15 Cartas de Antonio Requeijo (9-XII-1871) y Antonio Camba (20 y 24-I-1872) a Pallares: AHPL, CP, leg. 11.

16 La filiación alfonsina de los titulares de estos puestos se deduce de la consulta de la siguiente documentación: «Exposición que el Conde de Pallares presenta al Congreso de los Diputados, denunciando los hechos ocurridos en el distrito de Villalba en las elecciones de abril de 1872"e "Información sumaria a instancia del procurador D. Martin Eliodoro Rúa representando al Sr. Conde de Pallares, electo Senador del Reino, por la provincia de Lugo, sobre averiguación de hechos violentos ejecutados para neutralizar los electores que deseaban votar a dicho Sr. Conde como candidato de coalición y oposición en el partido de Villalba, los días 1 y 2 de abril de 1872" AHPL, CP, leg. 3.

17 Sobre las elecciones de abril de 1872: A. Bahamonde y J. A. Martinez, Historia de España. Siglo XIX, Madrid, Cátedra, p. 581; P. Anguera, Propaganda política i processos electorals al BaiX Camp: 1869-1873, Reus, Associació d'estudis reusencs, 1985, pp. 107 y ss.

18 M. Espadas Burgos, Alfonso XII y los origenes de la Restauración, Madrid, CSIC, 1975.
} 
sistentemente demandaba Cánovas. Alfonsistas procedentes del moderantismo que crean órganos de partido, que fundan periódicos, que participan (incluso con éxito) en el juego electoral del Sexenio y que, en sus elementos más visibles, comparten una común condición de acomodados propietarios agrarios, son los que se identifican en Lugo, y en cuanto tales su actividad debe de tomarse forzosamente en consideración a la hora de señalar las razones explicativas del exitoso experimento restaurador.

\section{LA REORGANIZACIÓN POLITICO-ADMINISTRATIVA DE LA PROVINCIA}

Con sólo echar una ojeada a los primeros números de la Gaceta de Madrid correspondientes a 1875 , se comprueba fácilmente que el primero y más urgente objetivo del flamante Ministerio-Regencia es la renovación del personal político-administrativo y su substitución por adictos a la nueva situación. Así, las relaciones de nuevos gobernadores civiles, de nuevos titulares de puestos de responsabilidad dentro del organigrama funcionarial, de nuevos jueces, asi como las disposiciones concediendo plenos poderes a los gobernadores para la renovación de diputaciones y ayuntamientos, se suceden casi sin solución de continuidad. Se trata, evidentemente, de purgar a la admínistración de elementos procedentes de la etapa revolucionaria y de garantizar en los nuevos una fidelidad absoluta al recién inaugurado orden de cosas, pero también de recompensar a las clientelas de los prohombres restauradores que con su actuación habian contribuido al final feliz de la aventura alfonsina. Por lo tanto, eran dos las metas a alcanzar, y si bien la primera hacía simplemente referencia a un orden general que se exigía fuese respetado por los nuevos inquilinos de las dependencias estatales, la segunda conllevaba implicaciones de carácter personal y singular por cuanto había que concretar quiénes serían esos nuevos inquilinos ( $\mathrm{y}$, lógicamente, quiénes quedarían fuera del reparto), elección obligada que podía, potencialmente, provocar tensiones entre los deseos del centro y los de sus apoyos repartidos por todo el país, como también entre los propios alfonsinos que se creian con derecho a recibir algún tipo de recompensa por su fidelidad en los años dificiles y que no estaban dispuestos a compartirla con los revolucionarios del día anterior. $Y$ todo ésto había que llevarlo a cabo atendiendo a los deseos de Cánovas de una restauración sin exclusiones, que olvidase el pasado y que diese cabida a todos cuantos manifestasen su adhesión a la monarquía de Alfonso XII, única forma de garantizar un mínimo consenso entre 
todas las fracciones de las clases dominantes que diese estabilidad al sistema ${ }^{19}$.

El análisis local es el único que permite constatar cómo se construye en la práctica este diseño teórico hasta el momento sólo presente en la mente de Cánovas. Para la provincia de Lugo, y comenzando por la Diputación, es el gobernador civil quien nominalmente se encarga (al igual que en el resto del país) de la definición de sus miembros ${ }^{20}$. La primera sorpresa (relativa) es que la renovación no alcanza, ni mucho menos, a la totalidad de la anterior corporación creada en 1874. De hecho, de un total de 46 diputados se mantienen nada menos que $22(47,8 \%)$, mientras que son $24(52,2 \%)$ los que ahora se incorporan pasando a ocupar un escaño en el palacio de la calle de San Marcos. Se configura así un nuevo poder provincial del que en absoluto se puede afirmar que esté dominado por un afán revanchista y en el que la continuidad se manifiesta claramente dando cabida a los recién adheridos y cumpliendo de este modo con los deseos de Cánovas, un continuismo que se refuerza si comparamos esta situación con lo ocurrido con ocasión del nombramiento de la nueva diputación en octubre de 1868, cuando sólo un diputado de la de 1867 repite representación en la nueva corporación revolucionaria. En este sentido, las diferencias entre el afán rupturista del Sexenio y la apuesta integradora de la Restauración son evidentes.

Por lo que se refiere a la caracterización de los miembros de esta seminueva diputación, hay un dato que destaca con fuerza: en ella están muy bien representadas las elites propietarias de la provincia, de tal modo que más del $66 \%$ de los diputados satisfacen contribuciones que superan las 200 ptas. (y el $83 \%$ más de 100), lo que los sitúa entre los mayores pagadores de sus respectivos ayuntamientos. Si a esto añadimos que nada menos que 10 de los 50 mayores contribuyentes por territorial de toda la provincia encuentran aquí asiento, el diseño de una diputación donde los

19 F. Gómez OChOA, "El conservadurismo canovista...", cit., pp. 133-35; C. ForCadell. ÁlvaREZ, "De la Revolución democrática a la Restauración: el horizonte de una historia social”, en $A$. Morales Moya y M. Esteban de VEga (eds.), La historia contemporánea en España, Salamanca, Ediciones Universidad, 1996, p. 111. Las dificultades para lograr esta Restauración integradora en Cataluña, con unos alfonsinos que aspiran únicamente a restablecer la situación pre-68, en $\mathrm{B}$. de Riquer i Permanyer, "Cánovas y los conservadores catalanes", en J. TUSELL y F. PORTERO (eds.), Antonio Cánovas y el sistema político de la Restauración, Madrid, Ed. Biblioteca Nueva, 1998, pp. 139-65.

20 Gaceta de Madrid, núm. 22, 22-1-1875. Se insiste especialmente en la necesidad de seguir un criterio no exclusivista en las renovaciones: los nombramientos se regirán por la independencia, probidad, inteligencia, propiedad, trabajo y honradez de los aspirantes, y no por sus antecedentes politicos. 
grupos de propietarios dominan con total claridad se hace aún más evidente. Por último, y cruzando este dato con el hecho de que en la inmediata corporación del Sexenio sólo 3 de estos 50 mayores pagadores estaban en ella representados, se puede afirmar que con la Restauración los más selectos representantes de los propietarios lucenses convierten a la diputación en una parcela propia de poder ${ }^{21}$. Si de lo que es la variable económica de los diputados pasamos ahora a la que define el particular currículo de cada uno de ellos en la corporación, nos encontramos con un nuevo dato que refuerza esa apuesta por la integración a la que ya nos hemos referido: el grupo mayoritario es el de los que inician su carrera política con el Sexenio $(38,6 \%)$ seguido por los novatos que la comienzan en $1875(34,1 \%)$, mientras que sólo el $27,3 \%$ disponen de experiencia datable antes de 1868. En otras palabras, no se puede en absoluto afirmar que la diputación restauradora permita una recuperación de lugares perdidos con la Revolución y que con la llegada de Alfonso XII retomen sus puestos viejos diputados isabelinos, sino que por el contrario domina una continuidad convenientemente aderezada con la savia nueva que aportan las incorporaciones de individuos por completo fieles a la recién inaugurada situación.

Sería, sin embargo, un error confundir esta evidente continuidad en el personal de la diputación con una indiscriminada postura de "borrón y cuenta nueva" que olvida por completo lo ocurrido en los años de la Gloriosa, porque nada hay de ésto. Así, con simplemente reparar en los individuos que durante el Sexenio habian ocupado los puestos de mayor responsabilidad en el organismo provincial (presidentes, vicepresidentes, secretarios, miembros de la Comisión Provincial) y, en general, en aquéllos que más claramente se habian significado como partidarios de la situación democrática, se constata su incomparecencia en la corporación provincial que nace con la Restauración: individuos como Policarpo Carrera, Antonio Castro Romay o Juan Paradela (presidentes en 1871, 1872 y 1874 , respectivamente), como José Casal o Antonio Martín Cid (vicepresidentes en 1869 y 1874), como Saturnino Suárez, Urbano de Bedia, José María Osorio, Manuel Mosquera o José Castro Freire (miembros en su día de la Comisión Provincial), o como Pedro Pozzi, Manuel Cociña o Domingo Paradela (todos integrantes del Comité Monárquico Constitucional creado en Lugo en 1869) son buenos ejemplos de una continuidad

21 Fuentes: las recogidas en la nota 14. Para la diputación de 1875 conocemos datos del $78,3 \%$ de los diputados, mientras que para la de 1874 el porcentaje se reduce al $63 \%$, hecho que dota a las conclusiones de una evidente provisionalidad y que obliga a manejarlas con suma precaución. 
discriminadora que al tiempo que acepta a revolucionarios del día anterior ahora milagrosamente convertidos en fervientes alfonsistas, también sabe protegerse de aquellos elementos cuyo pasado reciente convertía en poco recomendables y escasamente fiables a los ojos del nuevo poder ${ }^{22}$.

Desde un punto de vista legal, el gobernador civil es el encargado de la elección de los nuevos diputados, una decisión que luego debe de ser ratificada por el gobierno. Por lo tanto, y de conformarnos con este nivel de análisis, estariamos ante una muestra más de eficaz centralización en la que el ejecutivo, por vía de su representante en provincias, decide la composición de las diputaciones. Sin embargo, nada más lejos de la realidad. En este ejemplo lucense, es el propio gobernador quien aclara la paternidad de la nueva diputación, formada por los adictos de la anterior, por los diputados del distrito de Chantada que se encarga de nombrar Miguel Rodríguez Guerra (el moderado chantadino que había cedido su distrito en favor de Constantino de Ardanaz), por los que se incorporan recomendados por el conde de Pallares (que, además, resulta nombrado presidente de la diputación) y por aquéllos de la anterior que el mismo Pallares desea mantener ${ }^{23}$. Es decir, son los individuos que más méritos habían contraído en la lucha por la restauración quienes se encargan de los nombramientos, sin que en absoluto se pueda cargar esta responsabilidad en la singular persona del gobernador. Por lo tanto, son estos genuinos representantes de la periferia quienes juegan un papel más relevante en todo el proceso de recambio, algo por completo lógico si pensamos que nadie como ellos conoce la realidad política de la provincia, y que nadie como

\footnotetext{
22 La composición de la Comisión Provincial (como resulta ya conocido, un órgano vital en el funcionamiento de la diputación por su carácter permanente y sus atribuciones en materias tan sensibles como las quintas, el control financiero de los ayuntamientos o la revisión de los procesos electorales municipales) es otra prueba de una continuidad más presente en la forma que en el fondo: de sus cinco miembros, cuatro proceden de las filas alfonsistas (entre ellos su vicepresidente, Antonio Camba, que también to era del Comité Provincial Alfonsino) y sólo uno de las constitucionales.

23 Carta de Antonio de Medina (gobernador civil de Lugo) a Pallares (25-1-1875). En sucesivas correspondencias (26-I y 22-II-1875), Medina reafirma el papel del Conde en la creación de la diputación. Del mismo modo, también se concede una cierta intervención en los nombramientos a otros prohombres provincianos como el demócrata sarriano Matías López, reconociéndose asi su arraigo en el distrito: carta de Medina a Pallares (14-||-1875). Todas las correspondencias, en AHPL, CP, leg. 12. Aunque sin poder presentar pruebas empíricas, la permanencia en la corporación de hombres con destacada significación en el Sexenio como Manuel Estévez (varias veces integrante de la Comisión Provincial), hace indicar que también a su ilustre protector, el constitucional Augusto Ulloa (diputado por el distrito de A Fonsagrada en múltiples legislaturas y ministro de Gracia y Justicia en 1871 y de Estado en 1872 y 1874), se le reconoció algún derecho a intervenir en las designaciones (recordar que Ulloa fue de los primeros constitucionales en reconocer a Alfonso XII: D. ULLoA, Biografias gallegas. Historia y hechos de los personajes más importantes del país, Pontevedra, 1876, p. 37).
} 
ellos es capaz de ir más allá de las nominales y cambiantes etiquetas partidistas para señalar a aquéllos que mejor y más fielmente pueden servir a la nueva situación ${ }^{24}$.

Si del estudio de la diputación pasamos al de los municipios de la provincia (sobre los que también el gobernador tiene legalmente atribuciones en cuanto a su mantenimiento o renovación), podemos ratificar algunas de las ideas ya fijadas respecto de los diputados provinciales, pero también añadir nuevos elementos que completan el análisis y que confirman la importancia de los sujetos actuantes en la periferia en cuanto a la definición de los nuevos órganos de poder político-institucional, no dependientes en exclusiva ( $\mathrm{y}$ ni siquiera de modo predominante) de las determinaciones adoptadas en la lejana capital ${ }^{25}$. Comenzando por lo más evidente, las variaciones (sean sólo del alcalde, de una parte o de la totalidad de la corporación) afectan al $58 \%$ de los municipios, con lo que de nuevo se puede hablar de una recomposición sólo parcial que intenta hacer realidad en la periferia los ofrecimientos conciliadores presentados por Cánovas ${ }^{26}$. Sin embargo, también en este caso la alternativa de la continuidad/renovación está cargada de sentido y en absoluto puede entenderse como el

24 De hecho, en la decisión de mantener en la nueva diputación a individuos como los que reseñamos a continuación procedentes de la de 1874, juegan un papel decisivo criterios no estrictamente políticos que sólo elementos conocedores de la realidad provincial pueden apreciar: por ejemplo, Ramón Antonio Martínez, Antonio López Losada y Dositeo Neira Gayoso habían participado en las fiestas por la proclamación de Alfonso XII lo que les otorgaba la etiqueta de adheridos; Juan Soler y Mata carece de importancia política pero es fiel al gobernador; José María Osorio es amigo del alfonsino Antonio Camba y hace todo lo que éste Je ordena; Enrique Rodríguez Cortés tiene varios hermanos alfonsinos que pueden influir en sus decisiones políticas...: carta de Antonio de Medina a Pallares (25-1-1875): AHPL, CP, leg. 12.

25 Sobre las relaciones municipio-estado: E. TOSCAS I Santamans, L'estat i els poders locals a la Catalunya del segle $x \mid x$. Una visió des de Sarrià (1780-1860), Barcelona. Publicacions de l'Abadia de Montserrat, 1997.

26 Respecto de la caracterización económica de los titulares de alcaldias (disponemos de datos fiables para 48 de los 64 totales), y a diferencia de lo que sucedía en la diputación, es mayoritaria la presencia de los pequeños y medianos contribuyentes, con un $62,5 \%$ incluidos en el intervalo 50-100 ptas. Más significativo todavía es que únicamente el 18,7\% de los alcaldes figuran entre los 10 mayores pagadores de sus respectivos municipios. Aunque se trata sólo de una hipótesis a comprobar, entiendo que sería muy aventurado inferir de esta circunstancia un pretendido dominio político de estos pequeños y medianos propietarios en el rural lucense, por cuanto más probablemente se trate de individuos que actúan como delegados de aquéllos más poderosos interesados en el control de la administración local pero no dispuestos a arrostrar las penalidades de la acción política diaria. En este sentido, es muy útil la diferenciación que establece $E$. Toscas, en su estudio sobre el municipio de Sarrià, entre "poder formal» y "poder real» ( $L$ 'estat $i . . .$, cit., p. 166). Ver también, E. TOSCAS I Santamans, "Sobre la qüestió política local a mitjan segle xix. Aproximació a l'estudi de les relacions entre els poders locals i l'ajuntament al municipi de Sarrià en 1840-1856". Estudis d'història agrària, núm. 9 (1992), pp. 112 y 114; J. M. CARDESIN DiAz y P. LAGO PEÑAS, “Repensando el caciquismo: espacio político y agencia social en la Galicia de la Restauración». Historia y Crítica, núm. 2 (1992), pp. 212-13 y 221. 
simple resultado de una decisión adoptada por el gobernador civil. Para interpretar adecuadamente el complejo juego de intereses que se va a desarrollar en los primeros meses de 1875 en torno a la definición de las alcaldias lucenses, hay que partir de una consideración básica cual es la de su importancia en la gestación y reproducción de aquellas prácticas que sirven de sustento a las redes clientelares que, en los espacios locales, garantizan la influencia del político de turno. Tanto por la inmediatez y la proximidad con que se siente su poder, como por las importantes atribuciones que poseen y que regulan muy diferentes aspectos de la vida local, los ayuntamientos aparecen como codiciadas presas cuyo control garantiza un alto grado de influencia sobre el vecindario ${ }^{27}$. Éstas y otras razones que se podrían apuntar (como el papel que se reconoce a alcaldes y concejales en los procesos electorales o la pública ratificación, no simplemente simbólica, que de su poder obtiene todo político que logra el nombramiento de munícipes integrados en su clientela), explican la lucha enconada y las variadas influencias puestas en juego en este proceso de recomposición municipal, complejidad que invalida por superficial cualquier interpretación que de este hecho se quiera dar en clave centralista así como toda visión que prive de protagonismo a los poderes actuantes en el nivel del distrito y la provincia.

El estudio de la intensa correspondencia cruzada entre el gobernador civil de Lugo, Antonio de Medina, y un escogido elenco de individuos con probada fuerza electoral en sus respectivos distritos (muchos de ellos antiguos diputados a Cortes), demuestra con tozudez la elevada capacidad negociadora que reside en estos poderosos locales quienes, amparados tanto en su capacidad económica como en sus contactos políticos, logran imponer sus candidatos y configurar un poder concejil a la medida de sus necesidades y por completo fiel a sus dictados ${ }^{28}$. Hombres como el ya varias veces citado conde de Pallares (diputado a Cortes en 1857, 1863, 1871, 1872; mayor contribuyente en el ayuntamiento de Vilalba), como Miguel Rodríguez Guerra (ex-gobernador civil de Ba-

27 J. A. DurÁn, Historia de caciques, bandos e ideologías en la Galicia no urbana, Madrid, Siglo XXI; J. M. CAADESIN DiAZ, "Revolución liberal y poder político local: estabilidad y cambio en el mundo rural lucense", en J. M." DONÉzAR y M. PÉREZ LEDESMA (eds.), Antiguo Régimen y liberalismo. Homenaje a Miguel Artola, 2. Economia y sociedad, Madrid, Alianza-Universidad Autónoma de Madrid, 1995, pp. 441-452; M. GonzALEZ DE MOLINA, "La funcionalidad de los poderes locales en una economía orgánica", Noticiario de Historia Agraria, núm. 6 (1993), pp. 9-23; J.-P. Jessenne, Pouvoir au village et Révolution: Artois, 1760-1840, Lille, P.U.L., 1987; R. Romanell, "Autogoverno, funzioni pubbliche, classi dirigenti locali. Un'indagine del 1869", Passato e presente, núm. 4 (1983), pp. 35-83.

${ }_{28}^{28}$ La correspondencia aludida puede consultarse en el AHPL, CP, legs. 12 y 13. 
dajoz, diputado a Cortes en 1858, 1863, 1864, 1865; provincial en 1868; mayor contribuyente en el ayuntamiento de Chantada), como los hermanos Quiroga Vázquez (Vicente y Manuel, diputados a Cortes en 1869, 1871, 1872; mayores contribuyentes en Queiroga), como Casiano Pérez Batallón Losada (diputado a Cortes en 1867; mayor contribuyente en Sarria), como Bartolomé Basanta (diputado provincial entre 1871-75; mayor contribuyente en Viveiro), como Antonio Camba (diputado provincial de modo casi ininterrumpido entre 1859-75; presidente de la diputación en 1864-65) o como Manuel Rodríguez de Castro (diputado a Cortes por Monforte en 1871 y 1872) son los que, en grado variable aunque con notable ventaja para el conde de Pallares, van situando a individuos de su confianza al frente de las alcaldías dentro de un proceso en el que el papel del gobernador se reduce a poco más que mero transmisor al gobierno de los deseos de estos personajes, claves por su fuerza local para lograr un arraigo efectivo de la Restauración en la periferia y plenamente conscientes del poder que su posición les aporta de cara a cualquier negociación que implique puestos y recompensas para su clientela en el distrito.

Pretender que la determinación de los titulares de alcaldías respondiese en exclusiva a los deseos del gobernador en cuanto representante del poder central, hubiese precisado de dos condiciones que estaban muy lejos de cumplirse en la provincia de Lugo: 1) que tuviese la fuerza suficiente como para imponer su autoridad sobre los prohombres de la provincia $y, 2)$ que tuviese un completo y exacto conocimiento de la situación política lucense para poder reconocer entre los aspirantes a cargos concejiles a aquéllos mejor dispuestos y más preparados para servir a la nueva situación, un par de precondiciones que, a su vez, dependerian de una tercera igualmente inexistente como sería la disposición por el gobernador de un amplio funcionariado de fidelidad y obediencia dirigidas en exclusiva al Estado y que poder situar en primera linea de lucha frente a los poderosos locales. De hecho, incluso en aquellos ayuntamientos sobre los que no pesa la figura de un designador más o menos oficial y en los que el gobernador tiene las manos libres para actuar, se ve obligado a solicitar asesoramiento e informes a fin de no errar en las designaciones ( "hay mucho pretendiente carlista», afirma el gobernador Medina en carta al conde de Pallares, 15-III-1875), unas noticias que no proceden de asépticos funcionarios distribuidos por la provincia (que, en realidad, no son más que deudos de los políticos dominantes en el Sexenio) sino de individuos vinculados a algunos de los prohombres provinciales ya mencionados y que disponen de un conocimiento de primera mano sobre sus municipios, con lo que la primera autoridad de la provincia está recibiendo una 
información que se presenta convenientemente filtrada por el cedazo de los notables locales ${ }^{29}$.

El hecho de que la configuración del poder municipal esté fuertemente condicionada por las deferencias y contemplaciones debidas a los políticos adictos con fuerza propia en los distritos, no determina en absoluto que se trate de un proceso sencillo y carente de cualquier tipo de competencia. Bien al contrario, el que los nombramientos no vengan únicamente definidos por la superioridad provoca que en numerosos ayuntamientos se produzca un choque de intereses entre aquellos individuos que se consideran con derecho a realizarlos y que, además, son muy conscientes de la importancia de esta lucha local para asentar sus particulares parcelas de influencia en un momento en que, a nivel de todo el país, se está produciendo una reacomodación de poderes producto de la nueva situación política. Si ya de por sí este proceso resulta complicado (al efectuarse en un escenario preñado de personalismos, determinado por la defensa de intereses particulares y carente de organizaciones partidistas sólidas que sean capaces de generar e imponer consenso entre sus miembros), los deseos gubernamentales de que se lleve adelante sin exclusivismos y atendiendo con preferencia al criterio de la adhesión al nuevo rey no hacen sino complicarlo ${ }^{30}$. Por lo tanto, ahora no se trata exclusivamente de atender a gentes procedentes del moderantismo y a los alfonsistas fieles de las horas difíciles, sino que también hay que satisfacer a los recién adheridos que buscan recompensas por su recién estrenada fidelidad..., pero haciéndolo de tal modo que los primeros no se sientan agraviados y que los segundos no interpreten esta actitud como signo de debilidad: casi la cuadratura del círculo en la que el gobernador juega el papel más difícil e ingrato, obligado a lidiar con las órdenes madrileñas y con las presiones de los políticos provinciales en busca de una casi imposible síntesis.

Es en los ayuntamientos correspondientes a los distritos de Becerreá, A Fonsagrada, Mondoñedo, Sarria, Viveiro, Queiroga y Monforte (es decir, en siete de los once en que se divide la provincia), donde de detectan los mayores problemas a la hora de fijar los titulares del poder municipal ${ }^{31}$.

29 Es lo que ocurre, por ejemplo, con las alcaldías del distrito de Mondoñedo: cartas de Antonio de Medina al conde de Pallares (23 y 29-III-1875): AHPL, CP, leg. 12.

30 Los personalismos y la carencia de motivaciones partidistas o ideológicas que dominan el escenario politico lucense, en las cartas de Antonio de Medina a Pallares (25-11-1875) y a Francisco Silvela (28-II-1875. Las dificultades que acarrea en los nombramientos la política de conciliación gubernamental, en la carta de Medina a Pallares (29-1-1875). Las tres, en AHPL, CP, leg. 12.

31 En los restantes (Lugo, Vilalba, Ribadeo y Chantada) no tenemos noticias de problemas en este sentido 
Las razones son múltiples y no siempre fáciles de determinar, pero casi todas coinciden en un mismo punto: el complicado juego de influencias que los políticos con intereses en los distritos ponen en liza para lograr un dibujo satisfactorio del paisaje concejil, que convierte en imposible cualquier pretensión del gobernador por definir en solitario el lienzo y lo obliga a delicadas negociaciones (con la oferta canovista de conciliación constantemente planeando) en las que debe andar con pies de plomo para evitar agravios siempre potencialmente peligrosos. En unos casos (Becerreá), son las presiones que recibe el gobernador para que no realice variaciones recordándole la oferta integradora lanzada por Cánovas ${ }^{32}$; en otros (Fonsagrada, Mondoñedo) la dificultad estriba en el arraigo local y los contactos de que disponen en el centro del sistema los hombres que con más asiduidad detentan su representación en Cortes (Augusto Ulloa y Cándido Martínez Montenegro, respectivamente) y que, como tales, determinan la composición de los órganos municipales de gobierno, individuos que pese a su carácter de oposición gozan de protección en Madrid (de hecho, serán elegidos diputados en las elecciones de 1876) pero cuya influencia a nivel provincial conviene reducir para dejar claro que ahora son otros los que ordenan y mandan en Lugo: así, Ulloa sólo logra mantener dos de cinco alcaldías, en tanto que Martínez sufre la pérdida de todas ${ }^{33}$. Siguiendo con la relación de dificultades, tampoco faltan enfrentamientos con alfonsistas que reclaman un mayor protagonismo en la definición del poder municipal y que se consideran fuertemente agraviados por las condescendencias del gobierno con la oposición (Sarria), ni problemas en distritos (Viveiro) en los que la ausencia de alfonsinos con prestigio obliga a seguir instrucciones de constitucionales (eso sí, adheridos con fervor a la nueva monarquia) en las designaciones de alcaldes ${ }^{34}$. Pero

32 Cartas de V. Vázquez Curiel a A. de Medina (18-II-1875) y de A. de Medina a Pallares (26(I-1875). Las dos, en AHPL, CP, leg. 12.

33 Augusto Ulloa, de los constitucionales sagastinos en 1875 , había sido ministro Fomento (1864), de Gracia y Justicia (1871) y de Estado (1872, 1874), además de diputado por A Fonsagrada de modo casi ininterrumpido desde 1854. Sus relaciones de parentesco con familias influyentes del Lugo decimonónico lo dotaban de un gran arraigo local (pariente del marqués de Villaverde de Lima, de los Saco, los Somoza, los Montenegro, los Neira...). Además, su prestigio y pasado políticos le hacian merecedor del aprecio tanto de Cánovas como de Romero Robledo (carta de A. de Medina a Pallares, 6-1X-1875: AHPL, CP, leg. 12). Cándido Martínez Montenegro habia desempeñado el cargo de juez de paz en Mondoñedo, además de haber sido diputado provincial del distrito entre 1868 y 1871 y su diputado a Cortes en 1871 y 1872 . Contaba con una sólida clientela gracias a sus contactos familiares con los Pardo Montenegro (sobrino de José María Pardo Montenegro, diputado a Cortes en cinco ocasiones bajo Isabel II) y los Carrera (cuñado de Policarpo Carrera, diputado a Cortes en el Bienio Progresista).

${ }^{34}$ En el distrito de Sarria, el demócrata e industrial chocolatero Matias López (diputado en 1872) logra retener cinco de las siete alcaldias, provocando las iras del también sarriano Casiano 
son sobre todo los encontronazos que se producen entre los propios conservadores, todos ellos convencidos de su autoridad moral para exigir unas alcaldías favorables a sus intereses, los que más virulentos resultan $y$ en los que las influencias puestas en juego presentan una mayor categoria, llegando incluso a implicar directamente a nombres como los de Romero Robledo o Francisco Silvela. Las luchas intestinas que ahora se dan siven para demostrar, de un lado, la carencia absoluta de disciplina interna y de factores de cohesión ideológica dentro de las muy indefinidas agrupaciones políticas del momento (Monforte) ${ }^{35} \mathrm{y}$, de otro, lo simplista que resulta traducir las disputas en términos estrictamente políticos, cuando a menudo no son sino una prolongación de viejas disputas entre clanes familiares. Así explicaba A. de Medina la lucha por las alcaldias del distrito de Queiroga entre los hermanos Quiroga Vázquez y Manuel Batanero:

"En este pais donde todavia se conservan algunas reminiscencias feudales, es frecuente la lucha de preponderancia local, nunca de ideas políticas no conocidas casi y mal dirigidas siempre en la parte rural de Galicia, entre antiguas casas que se disputan la influencia por el gusto de dominar el mismo país y en esta situación se encuentran en el Valle de Quiroga” ${ }^{36}$.

Estamos, por lo tanto, ante un escenario municipal complejo y lleno de matices, en el que el protagonismo legal e institucional del gobernador civil tiene que compartir escena con un numeroso grupo de actores ubicados en la periferia que no se resignan a interpretar únicamente papeles secundarios, y que constantemente reclaman para sí una mayor presencia en el guión. Además, se constatan claramente las enormes dificultades para llevar a la práctica la publicitada conciliación canovista, y ésto por dos razones fundamentales: la primera, por los odios y rencillas personales y familiares que constantemente interfieren en las decisiones políticas, poco 0 nada autónomas del conjunto de las relaciones sociales y muy fuertemen-

\footnotetext{
Pérez Batalión Losada, diputado en 1866 y miembro de la Comisión Provincial del Partido Conservador que funciona en Lugo desde 1871: carta de A. de Medina a Pallares (15-VI-1875). En el de Viveiro, es el constitucional adherido Bartolomé Basanta (diputado provincial durante el Sexenio y futuro representante en Cortes) quien lleva la batuta en el tema de las alcaldías (por cierto, realizando variaciones que buscan atacar las bases locales de otro constitucional, el ex-diputado provincial Urbano de Bedia): cartas de B. Basanta a A. de Medina (23-III y 13-V-1875). Todas, en AHPL, CP, leg. 12.

35 Aquí la lucha por las alcaldias se produce entre Manuel Rodríguez de Castro (diputado a Cortes en 1871 y 1872) y Andrés Andrade, los dos oficialmente alfonsinos: carta de A. de Medina a Pallares (17-VI-1875): AHPL, CP, leg. 12.

${ }_{36}$ Carta de A. de Medina a Romero Robledo (11-VI-1875): AHPL, CP, leg. 12. Robledo era el apoyo de Manuel Batanero (de la casa de la Cuesta), en tanto Silvela era el de los Quiroga Vázquez (de la casa de Lamela).
} 
te influidas por ellas; y la segunda, por la muy diferente lectura que los acuerdos adoptados en el centro del sistema tienen en las provincias, pues lo que en origen es sólo una resolución adoptada friamente y atendiendo a criterios de alta política, se transforma al llegar a los distritos en una opción de poder y prestigio que introduce criterios discriminatorios entre los notables locales, y que se emplea para mostrar al conjunto de la colectividad la influencia efectiva de que cada uno dispone ante el gobierno ${ }^{37}$.

Si de las designaciones de alcaldes pasamos a las de los titulares de juzgados municipales, el panorama con que nos encontramos es muy similar, si bien con la particularidad de que la lucha entre los poderosos del distrito para lograr situar a sus adeptos se convierte en un enfrentamiento abierto en el que cada cual aprovecha todos los recursos a su alcance. Las razones de tal virulencia son fundamentalmente dos: 1) la importancia que se concede al control de la justicia en primera instancia, fuente cierta de influencia y poder en la comunidad local ${ }^{38}$, y 2) el hecho de que, por ley, en las designaciones ya no sólo intervenga uno de los poderes del Estado (el ejecutivo) sino que también lo haga el judicial, lo que introduce un nuevo elemento con el que igualmente hay que contar y que en absoluto renuncia a jugar su papel ${ }^{39}$. Además, y a diferencia del cargo de alcalde, el de juez municipal es un puesto retribuido, lo que no hace sino multiplicar el número de candidatos y dificultar todavía más la elección. En los nombramientos de diputados provinciales y alcaldes, ya hemos visto como el protagonismo de los poderes periféricos con fuerza en los distritos era más que evidente, y también hemos constatado como se intentaba compaginar el respeto debido a los recién adheridos con la necesaria recompensa a los alfonsistas que habian peleado por la Restauración y que ahora, más allá de las ofertas conciliadoras, se consideraban con derecho

37 Las numerosas reticencias que los alfonsinos con protagonismo en los años del Sexenio muestran ante los miramientos con antiguos revolucionarios, son la mejor muestra de estas dificultades: "concordia sí, pero cada cual en su puesto según sus antecedentes", "increibles me parecen los miramientos con los que hace unos dias gritaban abajo los Borbones y las tradiciones y viva la República" o "es escandaloso como se mira a los que no hace un año renegaban de la dinastia" son algunas expresiones que demuestran con claridad este sentimiento: cartas de J. $F$. Regueiro (20-II-1875), E. Fernández (18-III-1875) y J. Vergara (29-XI-1875) a Pallares: AHPL, CP, leg. 13.

38 M. SierRa Alonso, “Clientes, caciques y notables políticos: mecanismos de control electoral en la Sevilla de la Restauración", Trocadero, núm. 5 (1993), pp. 394-397; S. Cruz ARTACHO, Caciques y campesinos. Poder político, modernización agraria y conflictividad rural en Granada, 1890-1923, Madrid, Ediciones Libertarias-Ayuntamiento de Córdoba, 1994, pp. 303-382.

39 Es el regente de cada Audiencia (en el caso de Lugo, el de A Coruña) el encargado de elegir, entre los integrantes de las ternas que les presentan los titulares de juzgados de primera instancia, a los jueces municipales. 
a figurar como los nuevos amos de la provincia. Sin embargo, y para el caso de los jueces municipales, si bien se mantiene intacto el protagonismo de los notables locales, las condescendencias con los antiguos revolucionarios no aparecen por parte alguna: aquí el objetivo es recomponer por completo la justicia local con elementos cuya fidelidad conservadora no ofrezca dudas, pero no va a resultar fácil ${ }^{40}$.

Los problemas tienen su origen, como ya cabía suponer, en la firme oposición que los constitucionales presentan a toda variación que no atienda sus preferencias ${ }^{41}$, muy en especial en el caso de aquellos municipios en los que habian logrado mantener el control. Para ello cuentan con unos inestimables aliados como son los jueces de primera instancia, quienes no dudan en elevar ternas de futuros jueces municipales integradas por elementos adictos de aquellos políticos a los que, en definitiva, ellos mismos debían su nombramiento en los años del Sexenio. Así actúan el juez de A Fonsagrada (deudo del constitucional Augusto Ulloa), el de Mondoñedo (del también constitucional Cándido Martínez), el de Becerreá (calificado de sagastino), el de Lugo (que sitúa a republicanos y carlistas entre los candidatos), el de Sarria (del demócrata Matías López) o el de Viveiro (que sólo promociona a aspirantes de obediencia sagastina) ${ }^{42}$. Si a esta oposición en origen sumamos la determinación legalista del regente de la Audiencia de A Coruña, que se niega a aceptar las ternas paralelas elevadas por el gobernador lucense exigiéndole razón de las causas legales que incapacitan en su opinión a los individuos propuestos por los titulares de juzgados de primera instancia ${ }^{43}$, tendremos definido el esquema básico de una situación en la que, una vez más, cualquier interpretación simplista que pretenda presentar al poder judicial local surgido con Restauración como el resultado de la imposición sin más de los criterios del

40 En la circular que Francisco de Cárdenas (ministro de Gracia y Justicia) envía al gobernador de Lugo sobre el tema de los jueces municipales, exige que sean elegidos individuos capaces y honrados, pero también "fieles al Rey, a la monarquia constitucional y al gobierno" (18-V-1875: AHPL, CP, leg. 12). Sin embargo, nada se dice de evitar exclusivismos. El subrayado es nuestro.

41 Sumados a los que plantean los propios conservadores cuando no coinciden en los candidatos a presentar, situación bastante habitual en distritos donde son varias (y enfrentadas) las sensibilidades conservadoras en lucha (caso de Becerreá, Chantada o Monforte): cartas de A. de Medina a Pallares (28-V-1875) y de A. López Silva a A. de Medina (7-VI-1875). Las dos, en AHPL, CP, leg. 12.

42 Cartas de A. de Medina a Pallares (15 y 17-VI-1875): AHPL, CP, leg. 12. Medina, gobernador de Lugo, ante tan evidente oposición de los jueces, no duda en afirmar: "Lo cierto es que el gobierno puede decir que en Lugo y su provincia sólo cuenta con funcionarios que le son desafectos" (carta al conde de Pallares, 15-Vl-1875: ibid.).

43 Cartas de Vicente P. Calderón (19-Vl-1875) y del Fiscal de la Audiencia de A Coruña al gobernador de Lugo (21-VI-1875). Las dos, en AHPL, CP, leg. 12. 
gobierno, tiene que ser rechazada por no responder en absoluto a la realidad empírica al desatender el elevado protagonismo que recae en los políticos de la provincia. De hecho, la solución final de este complicado asunto, y a pesar de una más que presumible llamada de atención del ministro de Gracia y Justicia ante el regente de la Audiencia coruñesa, no resulta más que parcialmente favorable a los intereses conservadores, por cuanto los jueces designados para los municipios comprendidos en los distritos de Viveiro, A Fonsagrada y Mondoñedo son calificados por el propio gobernador Medina de sólo “regulares» ${ }^{44}$. Con razón se quejaba ante el conde de Pallares de que "es asunto el de que se trata (jueces municipales), en todos los distritos de la provincia, de lo más engorroso y difícil que he visto, porque las exigencias encontradas y las aspiraciones interesadas son terribles" ${ }^{45}$.

Junto a diputados provinciales, alcaldes y jueces de paz, también los funcionarios empleados en dependencias públicas son objeto de atención gubernamental. Las depuraciones y cesantías de burócratas con cada cambio de gobierno son una realidad bien conocida para la España isabelina, situación que no va a variar con la Restauración por cuanto la administración seguirá constituyendo un espacio abonado para premiar fidelidades clientelares ${ }^{46}$. Por lo tanto, nada extrañan las variaciones que se producen en la provincia de Lugo durante los primeros meses de 1875 , que suponen el cese o traslado de todos aquellos funcionarios que, por sus inclinaciones políticas, son de dudosa fidelidad a la monarquía. De este modo, carteros, personal de Hacienda, alcaides, porteros, estanqueros... ven como la caída de sus protectores supone también la suya y como sus puestos pasan a manos de gentes integradas en los círculos clientelares próximos al nuevo poder. El objetivo de los cambios es, de modo general, dotar a la burocracia estatal de empleados fieles y obedientes, pero mucho más demostrar públicamente que las cosas han cambiado y que ahora son otros individuos los que dominan la provincia y los

${ }_{44}$ Para la provincia de A Coruña el resultado no es mucho mejor: en carta al gobernador de Lugo, su homónimo coruñés afirma que el regente de la Audiencia ha nombrado 19 jueces de paz diferentes a los que él le había recomendado (19-VII-1875: AHPL, CP, leg. 12).

45 Carta de A. de Medina a Pallares (8-VI-1875): AHPL, CP, leg. 12. En otra de 17-V-1877 (ibid., leg. 14) no dudaba en afirmar que la designación de jueces municipales era más complicada de llevar adelante que unas elecciones a Cortes.

46 B. DE RiQuer I Permanyer, “Formes $\mathrm{i}$ instruments de poder a la Catalunya del segle XIX», en D. PLÁCIDO et al., lles. jornades de debat. El poder de l'Estat: evolució, força o raó, Reus, Edicións del Centre de Lectura, 1993, pp. 140-142; R. ZuRITA AldEguER, Notables, políticos y clientes. La política conservadora en Alicante, 1875-1898, Alicante, Instituto de Cultura "Juan Gil-Albert", 1996; M. SIERRA AlONSO, "La política del pacto" El sistema de la Restauración a través del partido conservador sevillano (1874-1923), Sevilla, Diputación, 1996. Las referencias podrian multiplicarse. 
que pueden hacer y deshacer en los distritos. De ahi que las remociones se singularicen e interpreten como ataques a los políticos que, como Augusto Ulloa o Cándido Martínez, más se habían significado en el Sexenio lucense y más habían empleado a la administración para demostrar su poder $^{47}$. En consecuencia, los recién nombrados se presentan igualmente como los protegidos de sus respectivos patronos (igual que ocurre con alcaldes y jueces) que así afirman su prestigio, recompensan fidelidades y se aseguran un trato administrativo favorable, generando de este modo una estructura funcionarial cuya fidelidad no se dirige neutralmente al Estado y ni tan siquiera a la facción política gobernante, sino directamente al político singular al que saben deben su destino: las decenas de cartas de agradecimiento que recibe el conde de Pallares por parte de aquéllos a los que ha conseguido (o recuperado) un destino, así lo demuestran. Por lo tanto, más que definir a la administración de partidista hay que hacerlo de clientelar y personalista, con una obediencia generalmente dirigida más hacia nombres y apellidos concretos que no hacia agrupaciones políticas y, en consecuencia, no como el producto de una irresistible centralización sino como el resultado de la actuación de los políticos con peso en la periferia.

Las correspondencias del gobernador lucense Antonio de Medina durante estos primeros meses de 1875 , muestran a un individuo a punto de ser superado por lo complicado del escenario y que en absoluto responde al tópico de todopoderoso funcionario dotado de una incontestable influencia oficial. Por el contrario, nos encontramos con un personaje dubitativo, que constantemente precisa del asesoramiento del conde de Pallares, quejoso por el escaso respeto que le demuestran los políticos provinciales y necesitado de un protector en Madrid (el mismo Pallares) que justifique sus actos antes la superioridad y que lo protega de cualquier golpe velado que a mis espaldas hayan podido asestarme ${ }^{48}$. Consciente de su papel y de la limitación de sus recursos, aparece antes como un intermediario que lucha por conciliar los intereses del centro y la periferia que no como el brazo ejecutor en la provincia de las órdenes gubernamentales, intentando evitar la ruptura del delicado consenso todavía en construcción y buscando que las relaciones entre las elites centrales y las

47 Cartas de A. de Medina (15-III y 17-IV-1875: AHPL, CP, leg. 12) y de M. Pardo (13-VII1875: ibid., leg. 13) a Pallares.

48. La correspondencia del gobernador Antonio de Medina está plagada de alusiones a los políticos lucenses, calificándolos en términos siempre negativos y acusándolos de no manifestar respeto alguno por su autoridad, de tal modo que "parece que el gobernador está aqui como un dominguillo presto a su servicio según las cartas imperiosas y desatentas que uno recibe" (carta a Pallares, 5-IV-1877: AHPL, CP, leg. 14. 
que tienen asiento en la periferia se rijan por criterios de respeto y salvaguardia mutuos. Pero si Antonio de Medina no se nos aparece como un campeón gubernamental ante el que los oponentes provinciales nada tienen que hacer, tampoco lo hace como una simple correa de transmisión de las instrucciones llegadas desde el centro, ni como un mero informador de la situación provincial carente de opinión propia ni, mucho menos, como un autómata falto por completo de iniciativa que se limita a cumplir con rígida exactitud hasta las más mínimas indicaciones llegadas de Madrid. Por el contrario, sus noticias de Lugo transmitidas a la superioridad van aderezadas con comentarios cualitativos que constituyen indicaciones claras de las, a su juicio, decisiones más convenientes a adoptar en cada momento, aportanto por lo tanto opinión y no sólo información. Pero Medina llegará mucho más lejos en su reivindicación de un espacio de actuación propio y no simplemente subordinado, manteniendo una actuación que lo llevará incluso a desobedecer las órdenes superiores $\mathrm{y}$, amparado en su conocimiento de la situación lucense, a adoptar iniciativas propias por completo contrarias a los deseos del ejecutivo.

En abril de 1875 recibia Medina órdenes estrictas de embargo de bienes a todos aquellos sospechosos de simpatías carlistas. Desde el primer momento manifiesta su profundo desagrado ante tal medida, que considera «impolítica" y como "una mala propaganda para la Restauración", entendiendo que el gobierno debería dejarle más campo libre para tratar este tema dado su superior conocimiento de la realidad provincial ${ }^{49}$. Inicialmente, se limita a pedir consejo a su interlocutor habitual en estos casos, el conde de Pallares, y a solicitarle su mediación ante el ministro de Gobernación para suavizar los embargos y limitar en lo posible las órdenes de destierro. En su opinión, los embargos son "justos" pero también "inoportunos e inconvenientes" a pesar de la numerosa presencia de partidarios carlistas en la provincia, corriéndose el riesgo de que con la adopción de una medida tan drástica se pierdan de modo definitivo individuos y familias aún no del todo irrecuperables para la causa restauradora. Finalmente, $y$ dando muestras de una actitud que en nada responde a la obediencia jerárquica que por su cargo se le supone, decide actuar con "parsimonia" y no ejecutar los embargos y destierros (que, a comienzos de mayo, ascendian ya a la cifra de 122 embargos y 70 destierros) ${ }^{50}$. leg. 12.

49 Cartas de A. de Medina a Pallares $(24,25,26,27,28$ y 29-IV; 1 y 4-V-1875): AHPL, CP.

50 Ignoro si finalmente Medina se vio obligado a dar curso a las medidas contra los carlistas, pero lo que si se puede afirmar es que sus intentos y los del conde de Pallares por limitarlas fueron conocidos en la provincia: carta de Gumersindo Laverde a Pallares (2-VIII-1875): AHPL, CP, leg. 13 
Similar postura de independencia guiada por un bien visible criterio propio adopta con ocasión de las elecciones a Cortes de 1876, en concreto respecto de los candidatos del distrito de Mondoñedo. Durante el Sexenio había sido el sagastino Cándido Martínez Montenegro quien con más asiduidad lograra el acta mindoniense (en 1871 y 1872), manifestando ahora, en 1876, idéntica pretensión. Todas las noticias de que disponemos para el distrito hablan de una amplia y sólida clientela (los candidistas, entre los que había no pocos empleados del gobierno a pesar de las depuraciones efectuadas ${ }^{51}$ ) agrupada en torno al abogado Martínez, apoyo que tenía dos grandes fuentes de origen: por un lado, los cargos que había desempeñado el aspirante tanto en el ayuntamiento (ex-juez de paz), como en la Diputación Provincial (representante mindoniense entre 1868 y 1871), como en el Congreso, que sin duda le habían permitido repartir no pocos favores entre sus incondicionales; por el otro, sus amplias conexiones familiares que lo emparentaban con dos de las familias políticamente más importantes de la zona, la de los Pardo Montenegro (encabezada por José María Pardo Montenegro, tío de Cándido y varias veces diputado a Cortes con Isabel II) y la de los Carrera (con Policarpo Carrera, diputado en el Bienio Progresista y cuñado de Martínez, al frente). Pero además de este sólido arraigo local, Cándido Martínez gozaba también de buenos contactos madrileños entre las que destaca Romero Robledo, el ministro de la Gobernación encargado de llevar adelante estas primeras elecciones de la Restauración ${ }^{52}$. Amparado en esta situación y en las promesas de respeto a los constitucionales adheridos hechas por Cánovas, Martínez consigue del gobierno una declaración de neutralidad en el distrito. Cuando la noticia llega a Lugo, la reacción del gobernador Medina es de una total contrariedad pues suponía paralizar toda la estrategia de apoyo al candidato conservador por Mondoñedo, Patricio del Seijo, además de perder toda la autoridad que como gobernador pudiese tener en el distrito una vez que era público y notorio su apoyo a Seijo. Pero de nuevo, y como ya había ocurrido en el tema carlista, Medina decide hacer oídos sordos y actuar por su cuenta: no hace pública la noticia de la neutralidad (que, no obstante, los apoyos de C. Martínez se encargan de difundir por todo el distrito) e incluso llega a redactar él mismo el manifiesto electoral de $\mathrm{P}$. del Seijo, asegurando "apretar» todo lo que puede en Mondoñedo para evitar el triunfo del constitucional que, no obstante, al final se produce en toda regla. En definitiva, lo que vienen a demostrar estas dos actuaciones del

51 Carta de A. de Medina a Pallares (26-l-1876) y papel suelto entre la correspondencia de 1876: AHPL, CP, leg. 12.

52 Carta de Pallares a Fernando Cos-Gayón (11-VI-1881): AHPL, CP, leg. 18 bis. 
gobernador lucense es, en primer lugar, lo inadecuado que resulta presentar la labor de estos representantes del gobierno como una simple prolongación de los deseos del ejecutivo, por cuanto un análisis más pormenorizado demuestra que no siempre es así y, en segundo lugar, la muy diferente lectura que una decisión tomada en el centro del sistema tiene al llegar a la periferia y afectar a colectivos concretos de individuos que aquí pugnan por salvaguardar su prestigio e intereses y que, como en los ejemplos repasados, puede degenerar en una traducción muy imperfecta de los deseos del centro. $Y$ es que, como manifestaba el gobernador Medina al recibir la orden de neutralidad en Mondoñedo, "¿Si éso (la neutralidad) se realiza, quién aguanta a esta gente. ¿Cómo queda Pedro Basanta que ahora trabaja de veras y los que nos ayudan en Foz, Abadín...? Esto es verdaderamente insutrible" (carta a Pallares: 31-XII-1875, AHPL, CP, leg. 12).

\section{EPILLOGO: LOS DIPUTADOS A CORTES}

La evidente realidad del encasillado gubernamental y de la generosa práctica del apoyo moral del ejecutivo a los aspirantes con carácter de oficiales, ha enturbiado en no pocos análisis el estudio en profundidad de los factores actuantes en la definición de los diputados a Cortes, quedando en muchas ocasiones la impresión de que la representación parlamentaria era únicamente el resultado de una compleja negociación urdida en el centro del sistema en la que el papel de los distritos era el de simples refrendadores pasivos de unos resultados ya decididos de antemano. ACtualmente, esta visión se está poniendo en duda, destacando algunos estudios la presencia de elecciones realmente competidas (aunque la competencia no siempre discurriese por cauces político-ideológicos sino por los clientelares y caciquiles propios del $s$. $x I x$ ) y otros el papel jugado por los poderes locales presentes en los distritos ${ }^{53}$. Negar, a estas alturas, el papel y la fuerza del gobierno en los procesos electorales seria un intento condenado al fracaso por el peso de las evidencias empíricas en contrario, pero tal realidad no quiere decir que residan en él todas las claves explicativas de los resultados electorales, porque no es así en absoluto. Aunque se trata únicamente del avance de un trabajo todavía en

53 Ver, por ejemplo, C. Frias CORREdor, Liberalismo y republicanismo en el Alto Aragón. Procesos electorales y cambios politicos, 1875-1898, Huesca, Ayuntamiento, 1992; M. A. PEÑA GUERRERO, Clientelismo politico y poderes periféricos durante la Restauración. Huelva, 1874-1923, Huelva, Universidad, 1998. En una linea diferente, 1. PEÑARRuBIA, "La expresión de la disidencia en una sociedad caciquil: Mallorca, 1875-1923". Historia Social, núm. 32 (1998), pp. 23-35. 
curso sobre las elecciones de diputados a Cortes en el Lugo de la Restauración, el análisis realizado sobre las tres primeras del período (1876, 1879 y 1881 , convocatorias que para esta provincia en concreto son muy significativas por marcar tendencias con clara proyección de futuro), demuestra el papel básico que juega para todo candidato el disponer de una amplia, fiel y bien predispuesta clientela local y de unos amplios contactos sociales a nivel del distrito, tanto o más necesarios para garantizar su éxito que el apoyo del gobierno (a menudo, decidido precisamente en función de esta fortaleza local). Así, la elección de diputados con arraigo y que cuentan con fuerza propia en los distritos (o bien con apoyos locales lo suficientemente potentes como para asegurarles su elección) es una constante en el Lugo de estos primeros años: Bartolomé Basanta y Francisco Sanz en Viveiro, Cándido Martínez en Mondoñedo, Augusto Ulloa (y a su muerte, Manuel Estévez y Pegerto Pardo Balmonte) en A Fonsagrada, Mariano Cancio Villaamil en Ribadeo, Antonio Salgado Somoza y Manuel Somoza de la Peña en Chantada, Miguel García Camba, Juan Bautista Neira y Manuel Becerra en Becerreá, Manuel y Vicente Quiroga Vázquez en Queiroga o Manuel Rodríguez de Castro y los hermanos Guitián en Monforte, todos ellos naturales de la provincia ${ }^{54}$, la mayoría nacidos en los distritos que representan y, además, todos cabezas de sólidas redes clientelares ubicadas en los espacios locales que incluyen desde dependientes agrarios y autoridades locales hasta familiares y parientes, son ejemplos bien visibles de esta realidad, obligando a introducir la variable representada por los poderes periféricos en toda investigación que intente ir un poco más allá de la mera apariencia superficial de las elecciones decimonónicas.

\footnotetext{
54 En estas tres elecciones, sólo tres diputados proceden de fuera de la provincia: José de Cárdenas (1876), Fernando Cos-Gayơn (1881) y Felipe González Vallarino (1879), pero únicamente este último responde a la tipología del cunero por haber sido prácticamente impuesto por el gobierno, en tanto que los otros dos fueron traídos a Lugo por expreso deseo del conde de Pallares (en el caso del varias veces ministro Cos-Gayón, incluso compitiendo con otros distritos que también pujaban por su presencia), deseoso de poder controlar la circunscripción de la capital recurriendo a un diputado foraneo que no ponga en peligro su hegemonia y liderazgo, y buscando además un buen contacto en Madrid que le ayude a llevar a buen puerto las numerosas peticiones que le llegan procedentes de su clientela lucense: X. R. VEIGA ALonso, O conde de Pallares e o seu tempo (1828-1908). Aproximación ó activismo das elites na Galicia decimonónica, Lugo, Deputación-El Progreso, 1999, pp. 334 y ss.
} 